\title{
CAN SIMULATIONS PERFORM DECISION-MAKING AND LEARNING PROCESSES OF TEAMS?
}

\author{
Riccardo Sartori, University of Verona, Verona, Italy \\ Andrea Ceschi, University of Verona, Verona, Italy \\ Ksenia Dorofeeva, University of Verona, Verona, Italy
}

dx.doi.org/10.18374/RBR-13-2.8

\begin{abstract}
This study aims to investigate which team factors have a significant influence on decision-making and on learning processes of teams. In order to understand which factors improve more, several relevant teams characteristics drawn from classical literature have been considered, such as: shared mental models (Anderson \& West, 1998; HÃartel, HÃartel, \& Barney, 1998), leadership (Scott \& Bruce, 1994), size of groups (Shaw, 1981). In particular, we focused on Teamwork and Team Climate and dimensions related such as: Flexibility (Patterson et al., 2005), Vision, Participative safety, Support for innovation and Task orientation (West \& Farr, 1990). Considering team simulation research (business simulation, virtual financial contest, data-management games etc.) we explored a set of relationships among factors presented, which reflect authentic causal relations with the learning processes and the decisions of teams. We establish that three dimensions, which are: Flexibility, Communication and Support for Innovations have a crucial role in all the simulation studied. In specific, Flexibility delights the team reaction and its turn effects on the decision-making of teams. Basically, when a team is more "flexible", members of the groups are more open to the innovations, participants feel supported by colleagues, they feel safe in the teamwork and the frequency of their interactions become higher. In addition, as result of these processes learning and decisions abilities improve. The study illustrates that such dimensions play a key role in acquiring information and in learning aims, and those are essential characteristics in order to register a good performance in decisions, by sharing information and knowledge inside the group.
\end{abstract}

Keywords: Teamwork, Team climate, Business simulation, Group learning, Decision making performance. 